\title{
Emancipation. From Introvert to Extrovert Critique
}

\author{
Rasmus Willig \\ Department of Society and Globalisation, Roskilde University, Roskilde, Denmark \\ Email: willig@ruc.dk
}

Received 2 June 2014; revised 5 July 2014; accepted 15 July 2014

Copyright @ 2014 by author and Scientific Research Publishing Inc.

This work is licensed under the Creative Commons Attribution International License (CC BY). http://creativecommons.org/licenses/by/4.0/

(c) (i) Open Access

\section{Abstract}

The article argues that the so-called life-coaches can be seen as exponents of the ongoing institutionalization of the introverted criticism that apparently leads to more self-criticism and to a feeling of failure rather than to an actual extroverted criticism of the structural conditions of society. Thus, the hypothesis is that the inner work with the resources of the self is so exhausting that it leads to a mental breakdown. The self becomes so exhausted that if it should make up its mind to criticize the structural conditions of society; the critique will be dismantled beforehand. But what then can be understood by the strong concept of "emancipation" today? In line with Critical Theory's model for emancipation, the article suggests that the historical alternative for our time consists in the liberation of the extroverted criticism. An actual and radical liberation of the possibilities for practicing criticism - that is, a democratization and establishment of a critical culture-is the moral potential for development, which must be promoted to pave the way for any future emancipatory movements.

\section{Keywords}

\section{Critical Theory, Herbert Marcuse, Emancipation}

\section{Introduction}

Critical Theory played a central—if not the most central-role in formulating social alternatives in the years before and after the student rebellion, and therefore it's highly relevant-now over 40 years after the rebellionto ask if the model for Critical Theory still has something to offer. The question that arises today is twofold: Is there a need for a reactualization of the existing Critical Theory at all, or is it time for the gathering of new and unexplored emancipatory potentials that are to be found in our own age rather than in the theoretical works of the past? 
As I see it, the answer lies somewhere between these two significant questions. There's no doubt about that the Critical Theory's model for historical progress is still intact. What is more unclear however is the question about which aims for the moral development that should constitute the frame for the question of emancipation. I will proceed in five steps in order to come closer to what emancipation can mean today. In the first step the focus would be on Herbert Marcuse, who undoubtedly was Critical Theory's most highly profiled representative in the student rebellion. What had been overshadowed by Marcuse's presence in connection with the student rebellions in Berlin, Frankfurt, Paris and especially in San Diego and Berkeley (Juutilainen 1996) however, was his precise and pedagogical descriptions of the structure of Critical Theory (I).

After this brief historical excursion to Marcuse I'll try-in a second step-to consider the predominant selfcriticism as a moral potential for development, if only the self-criticism is redirected from the self against the society. My point will be that the so-called self-realization coaches can be seen as exponents of the ongoing institutionalization of the introverted criticism that apparently leads to more self-criticism and to a feeling of failure rather than to an actual extroverted criticism of the structural conditions of society. Thus my hypothesis will be that the inner work with the resources of the self is so exhausting that it leads to a mental breakdown. The self becomes so exhausted that if it should make up its mind to criticize the structural conditions of society, the critique will be dismantled beforehand (II).

The concept of coaching comes from the world of tennis. No other player has been considered more angry and critical on the tennis court than John McEnroe. He made widely use of an extroverted criticism: hammered the racket in the ground and hit it against the net poles. Recently another professional tennis player directed his criticism introvertedly. He beat himself till he bled (III).

After these clarifications of the introverted criticism, I shall in a fourth step try to open up for, what can be understood by the strong concept of “emancipation” today. In line with Critical Theory’s model for emancipation, I will suggest that the historical alternative for our time consists in the liberation of the extroverted criticism. An actual and radical liberation of the possibilities for practicing criticism - that is, a democratization and establishment of a critical culture-is the moral potential for development, which must be promoted to pave the way for any future emancipatory movements (IV).

\section{Herbert Marcuse}

The task of Critical Theory has always been to identify potentials that can be made objects for emancipation. The overall task is subdivided in a sociological and a philosophical component. The sociological component consists in an elaborate explanation of the immanence - that is, the empirical reality — which apparently contains a not yet redeemed "normative surplus". The identification of such a "normative surplus" entails the finding out of the standards, which possess a moral potential of development and can lead to the liberation of the human development. In this transition, where an actual movement will take place, philosophy takes over. The methodological question that decided the validity of the sociological immanence-that is, the sustainability of the empiric power of expression—now becomes a question about the moral validity of the claims. Can they function as actual moral developmental goals for the human existence? Marcuse expresses it as follows: "To investigate the roots of these developments and examine their historical alternatives is part of the aim of a critical theory of contemporary society, a theory which analyzes society in the light of its used and used abused capabilities for improving the human condition (Marcuse, 1968)”. Thus the critical social theory rests upon the fundamental assumption that the human life is worth living, or rather: that it can and should be made worth living. The task of the critical analysis must therefore be to demonstrate the validity of these assumptions, and according to Marcuse the demonstration must take place on an empirical basis, because the established society already has an ascertainable quantitative and quality of intellectual and material resources at its disposal. He therefore asks: "How can these resources be used for the optimal development and satisfaction of individual need and faculties with a minimum of toil and misery?” (Marcuse, 1968). He continues: “The attempt to answer these questions demands a series of initial abstractions. In order to identify and define the possibilities of an optimal development, the critical theory must abstract from the actual organization and utilization of society's resources, and from the result of this organization and utilization. Such abstraction which refuses to accept the given universe of facts as final context of validation, such "transcending" analysis of the facts in the light of their arrested and denied possibilities, pertains to the very structure of social theory (Marcuse, 1968)”.

What is it that Marcuse tries to tell us? He tries to tell us that the possibilities for emancipation must lie inside 
the existing society, not in utopian ideas. The possibilities must be definable goals for practical efforts, and therefore the critical social theory must concern itself with the historical alternatives that already exist in the established society in the shape of alternative tendencies and powers. The value ascribed to these alternatives will not be realized until they are translated into reality through an historical practice. The theoretical concepts will only disappear, when society coincides with the redeemed claims.

On the basis of these guidelines for the construction of Critical Theory however, Marcuse states that the highly developed industrial society brings "critique in a situation where it's deprived of its very basis. Furthermore, he writes that "In the absence of demonstrable agents and agencies of social change, the critique is thus thrown back to a high level of abstraction" (Marcuse, 1968). Thus the pessimistic Marcuse doesn't mean that there exists any incentive for social change, and the criticism is forced back to a very high level of abstraction. According to Marcuse there is no longer any "ground on which theory and practice, thought and action meet. Even the most empirical analysis of his historical alternatives appears to be unrealistic speculation" (Marcuse, 1968).

Marcuse singled out, however, the creative force and the liberation of the libido as moral potentials of development (Marcuse, 1974), but presently these potentials seem to be reduced to compulsive creativity and pornofication of the public space respectively (Honneth, 2005). In this context I shall not try to decide, if these two moral goals for development still have some relevance or not, but instead take Marcuse at his words and examine, whether the criticism that the existing society absorbs for the benefit of its continuing dominance, can redeem a normative potential and pave the way for the chosen title of this text.

\section{The Inner Game of Tennis}

Many consider Timothy Gallway as the father of coaching. Gallway was a tennis coach, and in 1972 he wrote the book The Inner Game of Tennis, primarily meant for tennis players (Gallway, 1972). It was not intended for other parts of the human existence, but today it has acquired a sort of cult status among so-called life-coaches. The problem is that tennis-training is something quite different from the training of the self. The rules are different. Tennis matches and trophies can be won, when the other participants in the tournament are beaten. All players are subjected to the same rules. They are unambigous and cannot be changed. When tennis-training is used in others areas of life, it can end in disaster. The self can become so exhausted that it collapses.

A match is always played best of three sets (always the case in matches for women) of best of five sets. In other words: a match is over, when one of the players has won two or three sets. It is both the case in single and double matches. The counting goes as follows: If a player wins the first point in a game, he leads by 15-0, and if he also wins the second and the third point, the lead increases to 30-0 and 40-0 respectively. If the fourth point is also won, the player has won "the game"; but if both players have won three points, the score is "deuce" (40-40). The player that wins the next ball gets a so-called "advantage", and if the same player wins one more point, he has won the game, and so on. The rules are clear and cannot be changed.

One of the longest tennis matches of all time was played when Germany met USA in 1987. It lasted 6 hours and 34 minutes. The match was played between Boris Becker and John McEnroe. Becker won the match in five sets with the score 4-6, 15-13, 8-10, 6-2, and 6-2. The match became one of the longest of all time because the existing Davis Cup-rules required that every set was to be won with two points. This explains the very long sets. In principle the match could go on indefinitely because the tie-break did not exist. The result? The rules were subsequently changed and yes, Becker won, but for everyone that remembers the match the result also entailed the two worldclass players total collapse. 6 hours and 34 minutes is a long time, even for professionals.

Unlike tennis the training of the self follows no rules. There are no baseline, net or umpire. Each service, forehand or backhand can be ruled out or in. The rules are never clear, and if there is anything one can be sure of it is that rules never change.

McEnroe lost the match, and not even his coach needed to tell him that. But McEnroe was cheered. The match became his great comeback. Anyone who could play for so long time against the world's best tennis player was a winner. The match is still considered to be the match, where both players left the court as winners. There were no losers that day.

The new coaches who don't teach future tennis players, but future citizens to realize more of their talents have a much easier task than McEnroes coach. The tournaments of life are without finality (apart from death). There are always new matches to win or lose. Age sets no limits for the professionalized self-realization, and ends and 
means are also limitless. One can train towards any goals, and as to the means the imagination is the only limit. There are no rules for the training of the self, and of course it's always a bit worrying when everybody starts training without fixed or tested rules.

And maybe that is the reason why the result is more paradoxical than expected. Does the training not lead to a strengthening, but to an exhaustion of the self? When there is no final, there cannot be any breaks between the matches either.

Wherever neutral questions are asked, they are always critical. Questions serve to challenge ingrained habits, and that is what the coach does. He challenges and asks: Why is it so? What can you do to change it? The critical question is asked by the coach and is taken into the self. The "normal self” is split up, and a new "critical self” emerges, that watches the "normal self". Does one realize those parts of the self that the coach has questioned? Again and again the critical self asks the questions.

And what does realization mean? The prefix "re" comes from the latin word "res", which means "thing"—-so in a broader sense we have to do with a reification of the self. After many months of critical introspection the self is exhausted. It has run around itself and not found either talents nor abilities or skills that could be reified and consequently converted into money. But the coach has, because every lesson is paid for and it is not the dues for the tennis club.

For many people the encounter with a coach can be fatal. We have to dog with a genuine paradox: intended acts that lead to uintended consequences. It begins with a light mental tiredness, and the coach is contacted. Now the self needs to be freshed up, but after many hours of critical introspection the self has become still more exhausted (and poorer in financial terms). The consequence of locking up the criticism together with the self can be disastrous. The exhausted self collapses psychically. When the old Davis Cup rules were in force, Becker and McEnroe collapsed physically. When tennis coaching is applied to the practical conduct of life, it often leads to a mental collapse. The self is reified, has become the fossil fuel that is to be ignited. After some time it is burnt off and the self is burnt out.

\section{Code of Conduct}

In the conventional tennis game the players have to relate to their opponents and to the umpire. A certain kind of intersubjectivity is in play-though in a competitive situation-because the game is bound by standards, when there is more than one player on the court. It is a gentleman sport with an implicit code of conduct. Rule-breakers are criticized and a sentence is pronounced on the basis of established rules and standards. Most tennis clubs and associations have dress codes and rules for appropriate language, which seem outdated today, but nonetheless are still in use. Here is only a few of the rules of a tennis association chosen at random:

"Verbal Abuse: Players, and their supporters, shall not at any time verbally abuse any official, opponent, spectator or other person within the precincts of the tournament site. Verbal abuse is defined as any statement directed at another person that implies dishonesty or is derogatory, insulting or otherwise abusive. Audible Obscenity: Players, and their supporters, shall not use audible obscenities while on-site. An audible obscenity is defined as the use of words commonly known and understood to be profane and uttered clearly and loudly enough to be heard. Visible Obscenity: Players, and their supporters, shall not make obscene gestures while on-site. A visible obscenity is defined as the making of a sign with one's hands and/or racquet or balls that commonly have an obscene meaning”.

When a player breaks the rules, a critical sentence is pronounced, and the criticism is justified with reference to the written rules. The justification legitimizes and validates the criticism. Without the reference, no criticism.

Back to McEnroe, there is hardly anyone who cannot remember hasn't seen or heard about McEnroe's violent outburst of anger at Stockholm Open in 1984, where he after a series of shouts and screams cleared a tableful of water mugs with his racket. Although it was obvious that McEnroe went bananas and acted in a totally irrational way, it is possible to interpret his fit of rage as a criticism. McEnroe is the subject that criticizes, and the umpire is the object of the criticism. In McEnroe's opinion the umpire has made a mistake and refuses to change his verdict. In principle it is therefore the umpire, who first pronounces a critical verdict that McEnroe cannot accept. Thereby the umpire becomes an object of criticism, but because tennis is a gentleman sport that, as mentioned, has a very strict set of rules for appropriate conduct, McEnroe's behaviour quickly becomes the object of criticism. His criticism returns so to speak with a dialectical "backlash". The hitting of the water mugs and the abuse of the umpire resulted in a heavy penalty. A substantial fine had to be paid, and later McEnroe returned to 
Stockholm Open and apologized publicly for his behaviour. An apparently heavy penalty for a public repentance over a minor offence. The explanation has to be seen in connection to the very narrow limits for the appropriate behaviour in tennis, but not least and especially in connection to the fact that it was the hierarchy of the sport, which was attacked, that is: the umpire- the executive has the power to speak.

McEnroe was a very hot-headed fellow on the tennis court, and not only were the umpires' objects of his criticism: Importunate photographers as well as noisy spectators got a taste of his anger. His criticism however-like the umpire's—also had normative references. The balls that he saw as "in"-but the umpire as "out"represented violations of McEnroe's sense of justice, because they should have been seen as "in" according to the rules. The photographers who blitzed in the deciding moments of service, so that he made double faults, infringed upon the norm of total silence. The same was the case with the spectators, who didn't respect the silence either.

McEnroe's critical outbursts are very fine illustrations of the customary pattern of the criticism: a normative frame of reference is transgressed. An inner dissatisfaction is ignited, and a criticism is aimed at an external subject or object. There are loud protests against the umpire's verdicts or the condition of the court. The object of criticism is outside McEnroe's own self. Only at rare intervals he turns his criticism against himself for instance against the bad footwork or the unsuccessful long liners.

Recently however the professional tennis player Mikhail Youzhny hit himself with his racket till the blood flowed in an ATP master tournament. In his capacity of subject he didn't aim his criticism at an external object-as in the case of McEnroe-but made it into an internal matter. Only seldom the damages of the inner criticism are visible to the eye, but that was the case with Youzhny. A gash in the forehead for an exaggerated self-criticism. McEnroe's attack on the water mugs in Stockholm became famous, because it overstepped the bounds for a tennis player's possibility of showing his or hers extrovert criticism. Youzhny's "self-flagellation" -now over 20 years later-stands as a fine example of how the criticism is gaining a new pattern of movement. In the past the criticism changed from an inner to an external matter, but now the criticism returns to the self in a circular movement. From an internal to an internal matter, the criticism is kept inside the limits of the self. The criticism has become an internal, not an external matter. Anyone, who criticizes in public, also reveals himself as an individual, who cannot follow the predominant codes of conduct of the society.

The etymological root of "criticism" is the Greek word "krisis", which means "verdict" and/or "separation". I have already pointed out that our time in part is characterized by a distinct internal judgmental work with serious psychical consequences. I hope that I have made this thesis clearer. There are still external judges, but the number of internal verdicts is growing. We witness the construction of a self-appointed judgmental work scheme, where the self must split itself up in a number of functionally divided and specific legal positions: As counsel for the defence of the self, which is determined by the repetitive behaviour of the habits; As plaintiff against the accusations of the ideological background values; As judge in the decisive moment, a judge who confirms the necessary and appropriate punishments or rewards. After a sufficient amount of sentencing and verdicts the concept of criticism coincides with its etymological root, the crisis, the personal crisis.

In our kind of society criticism has apparently been institutionalized in private coaching sessions, not in public and social institutions. The coach has become the paid "critical friend", who gives lessons in the turning of the criticism against the self and not against the external structural conditions of the society. In the room with the friend the "client" says: "I am not good at...", and gets the answer: "What can you do to become better?" Both question and answer are formulated within the limits of society's "code of conduct"-but not against them.

Maybe it is no longer tennis that is played in our time, but a lonely game of pole tennis. The pole is the self, the ball the direction of the criticism, and the string the connection between the self and the criticism. What has become entangled and captured is the self: The ball is hit with a vengeance. The Coach shouts: "harder" and "you can self shout 'harder' and 'harder'! Let me hear you say it". The ball is hit even harder. The blows of the rackets point the direction. The strings are bursting. The criticism is fast and strong. When the ball is hit too hard, everything becomes entangled.

\section{Roads to Emancipation}

With the abovementioned examples of criticism's pattern of movement, it has been my aim to clarify how the social criticism has more or less disappeared as a consequence of the individualized criticism. In our society the inward-going criticism has become the predominant form of criticism. No matter how bad the surface is, it is not 
the court that's wrong; no matter how much the net sag or the balls are flat, I can only blame myself, not society. If the umpire passes a wrong sentence, it's probably all my fault. If I had used another argument, I would surely have gained sympathy. If the ball boys are too slow, again I can only blame myself, because I just have to be more patient. I must work more seriously with my patience. It's a part of the game, and I must learn it. Why does it have to be so difficult? It's my fault, not theirs.

With the criticism, the extroverted acts are weighed down by blame and a sense of guilt. Self-criticism has become the predominant form of criticism. No wonder then, that modern diseases have an "unheard of selfcriticism" in common. The "unheard" should be taken literally. The self-criticism is unheard in so far as nobody can hear or share it, as long as it is locked up behind society's strict standards for what may be said or not, and it's unheard in so far as the self-criticism has never been more powerful. It's more powerful than it ought to be and that is the explanation of the psychical collapse.

Marcuse's point was that criticism had been forced to such a high level of abstraction that it had lost the capacity for being an emancipatory incentive. Unlike Marcuse, I will stress-now 40 years later-that it is no longer forced to concern itself with external matters on a far too high level of abstraction, but have to attend to internal matters so tangible that they have turned into individual sufferings.

The subject of the essay has not so much been society's “tournaments" of endless competitions, but rather the possibilities for practicing criticism. The prevailing wave of individualization not only entails more freedom to manage the potentials of the self, but also a compulsion to manage the self in such a way that it plays on the dominant social terms.

The self has become a hyphenated word. Much can be linked with the self: self-development, self-management, self-regulation, self-realisation, self-awareness, self-esteem, self-confidence and self-acceptance, and there will probably be more to come as the individualisation wave rises. There is, however, a negative side to all this, which can take the form of a number of other hyphenated words, such as self-attack, self-chastisement and selfdestruction.

Briefly put, the downside of individualisation is concerned with all the expectations of self-realisation that cannot be achieved. Did I do things well enough? Could I have done things differently? Did I make the right choices? Today, modern individuals are required to continually examine their "accounts". They are constantly drawing up "internal self-assessments" of their successes and failures, and the result may well be negative when all the items are totted up. Such individualised self-assessments take no account of debtors. There is no one else to take the blame for failures or bad investments; only the self can try to mitigate the losses or, in the worst case, go psychologically bankrupt. This is the natural consequence of the increased demands for self-responsibility. Like any other constructional enterprise, the demand that we should be the architects of our own well-being is a risky and chance-governed undertaking which may well have psychological consequences.

In the introduction to his book Eliminating Self-Criticism, Allen Ross writes that self-criticism lurks just beneath the surface of the modern individual, from which hiding place it can cause you to feel depressed, guilty, irritable, inadequate, repressed or a failure. Ross believes that such self-criticism can be so severe that it should really be described as an attack - a process that is only negative, and which, according to Ross, brings about “inner turmoil”. In his book Toxic Criticism (Ross, 2009), Eric Maisel writes that self-criticism can damage our self-confi- dence. He feels that "almost nothing can do more psychological harm than criticism" and that "criticism comes at us from the past, as bad memories and as our own introjected 'inner critic"”. Self-criticism, as the title of Maisel's book suggests, is toxic to the self (Maisel, 2006).

It is to a large extent this internal auditing work that leads to destructive self-criticism, which can be seen as a genuine pathology of inadequacy. The inadequacy lies in the fact that the self cannot meet the demand to be self-responsible and self-managing, and instead of criticising the societal demands for individual audits, it turns the criticism inwards on itself.

The dialectical setbacks of individualism comprise in many respects an overlooked phenomenon, in which those hit by the boomerang effect have not yet come together and put into words the underlying causes of the toxic self-criticism. All we seem to have are the psychological self-help books, such as Embracing Your Inner Critic: Turning Self-Criticism into a Creative Asset by the Hal and Sidra Stone (Stone, 2009). Such books appear to offer help but note that little word “asset”. Self-criticism must be transformed into an asset, and thereby increase the value of the self. Once again, the inner accounts have to be audited.

Unfortunately, most of these self-help books offer the same formulas that gave rise to the toxic self-criticism itself; even where we seek help, we are thrown back upon our own resources. Individualisation has not only 
given people more opportunities to construct an independent identity, but also the opportunity for self-destruction-an "opportunity" that sociology often neglects to explore.

In order to play the game as well as possible, one hires a coach, and the coercive relation is completed-hand in hand with the self-criticism and the loss of the social criticism. In the future the possibilities for practicing criticism must be so radically grounded that it may be justified to say that it is no longer the question about coercive conditions, but about actual free choices for criticism's patterns of movements.

It is time to examine the consequences of the legally ensured freedom of the press, of speech, of assembly and of research — and not the least the normative conditions, which shall guarantee that the social criticism is praised and not considered as "the losers"” confessions to the social "code of conduct", because these legal and normative conditions are in their ends and means for balancing criticism's pattern of movement.

Today the normative surplus and the historical alternative to our age consist in the liberation of the extroverted criticism's possibilities of being. If the concept of emancipation means anything today it is the effort to guarantee the transcendent dimension of the criticism.

\section{References}

Honneth, A. B. (2005). Verdinglichung: Eine anerkennungstheoretische Studie. Frankfurt am Main: Suhrkamp verlag. Juutilainen, P. A. (1996). Herbert's Hippopotamus: A Story about Revolution in Paradise. (Movie).

Marcuse, H. (1968). One Dimensional Man: Studies in the Ideology of Advanced Industrial Societies. London: Routledge \& Kegan Paul Ltd., $\mathrm{x}$.

Marcuse, Herbert (1974). Eros and Civilization: A Philosophical Inquiry into Freud. Boston, MA: Beacon Press.

Maisel, E. (2006). Toxic Criticism. New York, NY: McGraw-Hill.

Gallway, T. (1972). The Inner Game of Tennis: The Classic Guide to the Mental Side of Peak Performance. New York, NY: Random House Trade Paperbacks.

Ross, A. (2009). Eliminating Self-Criticism. New York, NY: Allan Ross Publishers.

Stone, S. (1993). Embracing Your Inner Critic: Turning Self-Criticism into a Creative Asset. New York, NY: Harper Collins Publishers 
Scientific Research Publishing (SCIRP) is one of the largest Open Access journal publishers. It is currently publishing more than 200 open access, online, peer-reviewed journals covering a wide range of academic disciplines. SCIRP serves the worldwide academic communities and contributes to the progress and application of science with its publication.

Other selected journals from SCIRP are listed as below. Submit your manuscript to us via either submit@scirp.org or Online Submission Portal.
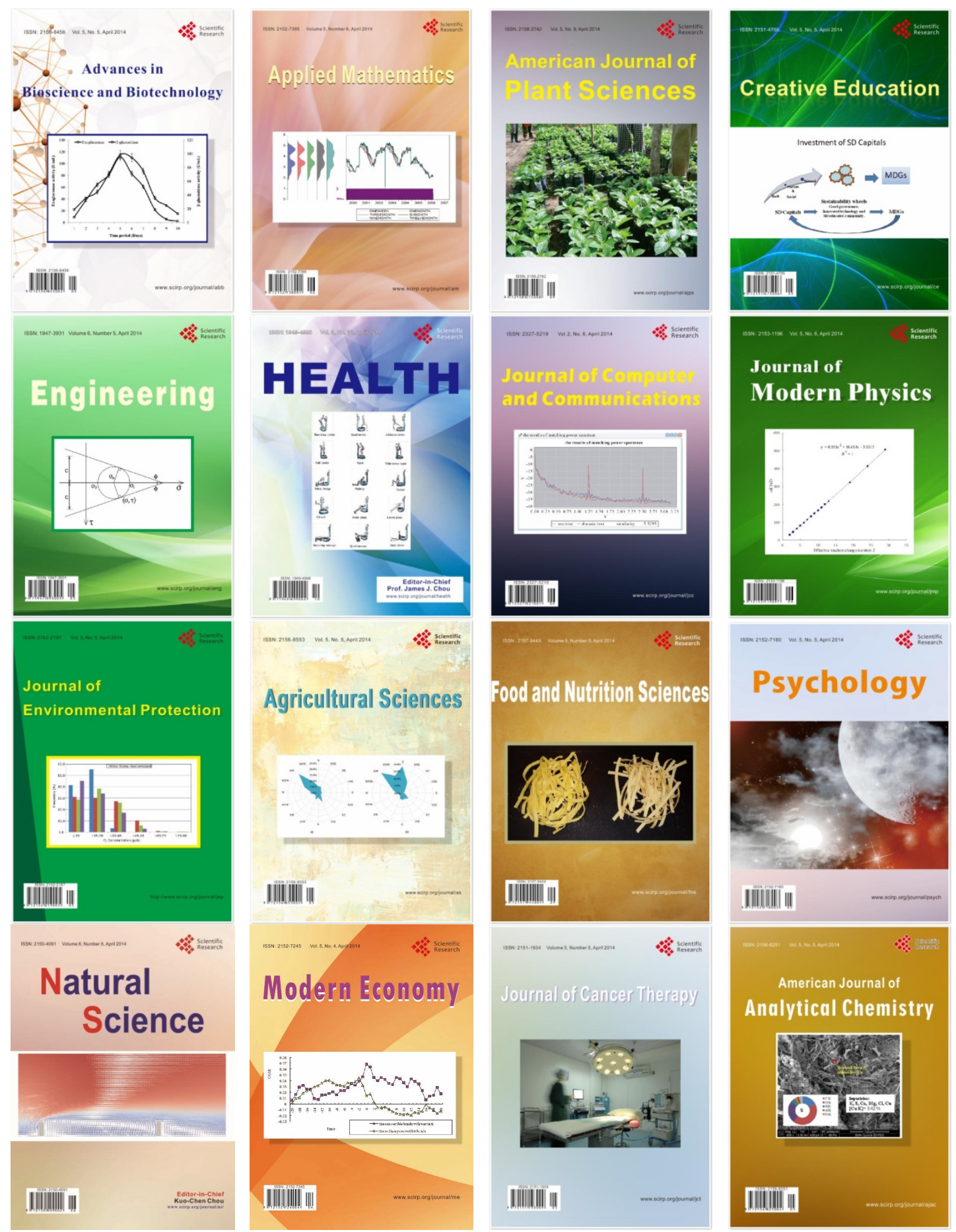